\title{
Operative versus nonoperative interventions for common fractures of the clavicle: a meta-analysis of randomized controlled trials
}

\author{
Tahira Devji BSc, Ydo Kleinlugtenbelt MD, Nathan Evaniew MD, Bill Ristevski MD MSc, \\ Shoghag Khoudigian BSc, Mohit Bhandari MD PhD
}

\section{Abstract}

Background: The popularity of surgery for acute displaced midshaft clavicle fractures has been fuelled by early randomized controlled trials (RCTs) showing improved rates of radiographic union and perceived functional benefits compared with nonoperative approaches. We performed a meta-analysis to determine the effect of operative and nonoperative interventions on the risk of secondary operation and complications and on long-term function.

Methods: We search MEDLINE, Embase and the Cochrane Central Register of Controlled Trials for reports of relevant RCTs published to Mar. 7, 2014. Two reviewers assessed eligibility of potential reports and the risk of bias of included trials. The Grading of Recommendations Assessment, Development and Evaluation approach was used to summarize the quality of evidence for all outcomes.

Results: We included 15 RCTs (9 trials comparing operative and nonoperative interventions, 5 comparing implants for operative treatment, and 1 comparing nonoperative treatments). Nonoperative treatments did not differ from operative treatments in the risk of secondary operation (risk ratio [RR] 1.16, 95\% confidence interval $[\mathrm{Cl}] 0.58$ to 2.35 ) or all complications $(\mathrm{RR} 0.90,95 \% \mathrm{Cl} 0.55$ to 1.50). One in 4 patients had a complication regardless of the treatment approach. Differences in functional outcomes, although smaller than the threshold for minimal important differences at 1 year, favoured operative interventions (standardized mean difference $0.38,95 \% \mathrm{Cl} 0$ to 0.75 ). Evidence for the type of implant or approach to nonoperative treatment remained inconclusive.

Interpretation: Current evidence does not support the routine use of internal fixation for the treatment of displaced midshaft clavicle fractures. Complication rates were high regardless of the treatment approach.

lavicle fractures are common injuries, affecting about 22000 Canadians each year and numbering 1.75 million fractures worldwide. ${ }^{1-6}$ The majority of these fractures are located in the midshaft, accounting for about $80 \%$ of all clavicle fractures. ${ }^{1,2}$ Closed midshaft fractures were traditionally treated nonoperatively, a practice largely based on previous studies by Neer and Rowe. ${ }^{7,8}$ In the last decade, evidence challenged the standard of nonoperative treatment, reporting high rates of nonunion $(15 \%-20 \%)$, poor early function, and residual sequelae at 6 months following nonoperative management in up to $42 \%$ of patients. ${ }^{9}$ Small clinical trials that followed have fuelled a growing popularity to treat these fractures surgically with plates and screws or intramedullary devices; however, these procedures carry inherent surgical risks for infection, implant failure and hardware irritation requiring subsequent removal. ${ }^{10,11}$

Whether surgery or a conservative approach is the optimal method of management for midshaft clavicle fractures is still an issue of debate. Several trials have compared operative and nonoperative approaches to treatment. In the last 5 years, a number of trials have also investigated various surgical tech- niques and the use of different implants. Previous reviews focused only on the operative versus nonoperative debate. . $^{1,911,12}$ Our review adds to this body of literature by providing data from the largest and most recent trial. It also provides a summary of the evidence on surgical techniques for these injuries, as well as nonsurgical options.

We performed a meta-analysis to determine the effect of operative and nonoperative interventions for treating acute displaced midshaft clavicle fractures on the risk of secondary operation and all complications and on long-term function.

Competing interests: Mohit Bhandari has received consultancy fees from Smith \& Nephew, Stryker, Amgen, Zimmer, Moximed, Bioventus, Merck, Eli Lilly and Sanofi; he was involved in research funded by Smith \& Nephew, DePuy, Eli Lilly, Bioventus, Stryker, Zimmer and Amgen. No other competing interests were declared.

This article has been peer reviewed.

Correspondence to: Mohit Bhandari, bhandam@mcmaster.ca

CMAJ Open 2015. DOI:10.9778/cmajo.20140130 


\section{Methods}

We conducted this study according to the methods outlined in the Cochrane Handbook for Systematic Reviews of Interventions. ${ }^{13} \mathrm{We}$ report our findings in accordance with the Preferred Reporting Items for Systematic Reviews and MetaAnalyses (PRISMA) statement. ${ }^{14}$

\section{Literature search}

We systematically searched MEDLINE (from 1946), Embase (from 1974) and the Cochrane Central Register of Controlled Trials (CENTRAL; from 1948) for articles published up to and including Mar. 7, 2014. Subject headings and subheadings (MeSH terms in MEDLINE and EMTREE terms in Embase) were used in various combinations and supplemented with free text (an example of the search strategy is available in Appendix 1, www.cmajopen.ca/content/3/4/E396/suppl/DC1). An RCT filter developed by the Health Information Research Unit at McMaster University ${ }^{15}$ was applied to the search. No restrictions on language or publication date were applied. Manual searches of the reference lists of key articles and of "related articles" featured in PubMed were conducted to identify additional articles. We searched conference proceedings (American Academy of Orthopaedic Surgeons, Canadian Orthopaedic Association and Orthopaedic Trauma Association) from the last 5 years and ClinicalTrials.gov to identify relevant unpublished studies.

\section{Study selection}

We included RCTs comparing any form of operative or nonoperative interventions for acute displaced midshaft clavicle fractures in patients 16 years of age or older. This included studies comparing operative and nonoperative interventions, studies comparing operative implants and studies comparing nonoperative interventions. Two reviewers (T.D. and Y.K.), both with methodologic expertise and one with content expertise, independently screened all titles and abstracts of reports identified through the literature search. Disagreements were carried forward for full-text review. Both reviewers independently reviewed the full text of potentially eligible reports; disagreements were resolved through a consensus process to determine final eligibility.

\section{Data extraction and quality assessment}

The same 2 reviewers independently extracted study data using a piloted electronic data collection form. Authors of the included studies were contacted if important data were unclear or not reported. When information was reported by graphical analyses only, the data were derived from the figures using graph digitizing software (GraphClick, Arizona Software).

The primary outcomes for this review were secondary operation, all complications and long-term function $(\geq 1 \mathrm{yr})$. We did not include routine removal of hardware as a secondary operation, because only studies of pin fixation versus nonoperative treatment reported routine removal following fracture healing. This procedure is typically done under local anesthesia with minimal sedation, requires a small incision over the tip of the nail and is not likely to result in complications. Conversely, plate removal is usually indicated as a result of discomfort and necessitates new admission, surgery under general anesthesia and an additional large incision. Thus, we included only removals that had an indication for removal such as infection, irritation or implant failure. Complications included symptomatic malunion, symptomatic nonunion, loss of primary reduction, hardware irritation, infection, neurologic symptoms, and other issues requiring surgical treatment. The selected complications were chosen because they are considered to be patient-important outcomes or were commonly reported in the identified primary studies.

For the assessment of methodologic quality, both reviewers independently assessed the risk of bias in included trials using the Cochrane Collaboration's risk-of-bias tool. ${ }^{13}$ They evaluated the quality of evidence in included trials for each outcome using the GRADE approach. ${ }^{16}$ Data from RCTs were considered high-quality evidence, but the quality could be rated down because of risk of bias, inconsistency, imprecision, indirectness or publication bias.

\section{Data synthesis}

We used risk ratios (RRs) to summarize results for secondary operation and all complications and mean differences to summarize results for functional outcome scores.

We pooled data on secondary operations and all complications from only trials that reported these outcomes; we calculated RRs using the Mantel-Haenszel method and a randomeffects model. ${ }^{13}$ The nature and criteria of the primary outcomes selected for our review were such that patients experiencing an event would require surgical intervention or additional medical management. We performed a "none has event" analysis, a variation of "analysis as randomized," 17 because it is highly plausible that most patients would return for follow-up if unsatisfied with treatment or experienced an adverse event. All patients included at randomization comprised the denominator; those lost to follow-up were assumed to not have had an event. ${ }^{17}$ Because some patients lost to follow-up may have experienced an event and sought treatment elsewhere, we performed 2 sensitivity analyses to test the robustness of the assumption made in our primary analysis and investigate the effects of dropouts and exclusions: (a) a complete case analysis and (b) an arm-level assumption analysis, in which the relative incidence among patients with missing data was assigned the same incidence as those followed up in the same study arm. ${ }^{17}$

We performed a complete case analysis and used standard mean differences (SMDs) to summarize results for long-term function. The SMDs were weighted according to the inverse variance method and pooled using a random-effects model. ${ }^{13,18,19}$ Minimal important differences (MIDs) were incorporated to aid the interpretation of treatment effects. The MID describes the smallest effect that an informed patient would perceive as beneficial enough to justify a change in management. ${ }^{20-24}$ The MID for the Disabilities of the Arm, Shoulder and Hand (DASH) questionnaire is estimated to be 10.2 points, ${ }^{25,26}$ which was converted to units of standard deviation (SD) using the DASH median SD for each comparison. ${ }^{27} \mathrm{~A}$ zone of clinical equivalence based on the converted MID was projected onto the forest plot to aid interpretability of the pooled SMDs. 


\section{OPEN}

Research

We quantified heterogeneity using the $\chi^{2}$ test for heterogeneity and the $I^{2}$ statistic. ${ }^{13} \mathrm{We}$ developed a priori hypotheses to explain potentially high heterogeneity in treatment effects across trials between intramedullary and plate fixation, between immediate and delayed (1-4 wk) surgical intervention, between 2-fragment and comminuted fractures, and between the presence and absence of selection or detection bias.

We evaluated interobserver agreement for assessments of study eligibility using the Cohen $\kappa$ coefficient, and we evaluated interobserver agreement for risk-of-bias assessments using weighted $\kappa$ coefficients; ${ }^{28,29}$ all coefficients were calculated using SPSS software (version 21.0; SPSS Inc.). All tests of significance were 2 -tailed, and $p$ values of less than 0.05 were considered significant. To assess for publication bias, we visually inspected a funnel plot for the outcome of longterm function. ${ }^{13}$ The forest plots and funnel plot were generated using Review Manager software (RevMan version 5.2; Nordic Cochrane Centre, Cochrane Collaboration).

\section{Results}

\section{Study characteristics}

We identified 422 potentially relevant citations through the literature search. Fifteen of these studies proved eligible for inclusion (Figure 1). ${ }^{5,10,30-42}$ The overall agreement between the 2 reviewers for final eligibility was excellent $(\kappa$ value $=0.94,95 \%$ confidence interval [CI $0.84-1$ ). All 15 studies were published between 2007 and 2013; their characteristics are summarized in Table 1. Nine studies compared operative with nonoperative treatment. ${ }^{5,10,30-36}$ Two-year follow-up data from one of the trials ${ }^{10}$ was reported in a separate publication. ${ }^{43}$ Five studies compared different operative implants. ${ }^{37-41}$ One placebo-controlled trial managed all fractures nonoperatively. ${ }^{42}$ Twelve studies were reported in English. The other 3 studies $^{31,33,38}$ were translated by reviewers with expertise in systematic review methodology.

The findings from the risk-of-bias assessment are shown in Figure 2. All 15 studies were found to have an uncertain to high overall risk of bias. Blinding of participants and outcome

Table 1: Characteristics of the studies included in the systematic review

\begin{tabular}{|c|c|c|c|c|c|c|c|}
\hline Study & Country & $\begin{array}{l}\text { Sample } \\
\text { size }\end{array}$ & $\%$ males & $\begin{array}{l}\text { Mean } \\
\text { age, yr }\end{array}$ & $\begin{array}{l}\text { Length of } \\
\text { follow-up, mo* }\end{array}$ & Intervention & Comparison \\
\hline Chen et al., $2011^{30}$ & China & 60 & 53 & 38.7 & $15(10-20)$ & TEN & Sling \\
\hline COTS $^{10}$ & Canada & 132 & 78 & 33.5 & $12 \ddagger$ & $\begin{array}{l}\text { Open reduction } \\
\text { plate fixation§ }\end{array}$ & Sling \\
\hline Figueiredo et al., $2008^{31}$ & Brazil & 50 & 78 & 30.2 & 24 & DCP Al plate & Sling \\
\hline Judd et al., $2009^{32}$ & United States & 57 & 91 & 26.5 & 12 & Modified Hagie pin & Sling \\
\hline Koch et al., $2008^{33}$ & Germany & 68 & 66 & 35.4 & $19.1(8-26)$ & Intramedullary pin & $\begin{array}{l}\text { Figure-of- } 8 \\
\text { bandage }\end{array}$ \\
\hline $\begin{array}{l}\text { Mirzatolooei et al., } \\
2011^{34} \dagger\end{array}$ & Iran & 60 & 82 & 35.6 & 12 & $\begin{array}{l}\text { Reconstruction } \\
\text { plate on superior } \\
\text { surface }\end{array}$ & Sling \\
\hline Robinson et al., $2013^{5}$ & United Kingdom & 200 & 88 & 32.4 & 12 & Locking plate & Collar and cuff \\
\hline Smekal et al., $2009^{35}$ & Austria & 68 & 87 & 37.7 & 24 & TEN & Sling \\
\hline Virtanen et al., $2012^{36}$ & Finland & 60 & 87 & 36.7 & 12 & $\begin{array}{l}\text { Reconstruction } \\
\text { plate on anterior } \\
\text { surface }\end{array}$ & Sling \\
\hline Assobhi et al., $2011^{37}$ & Egypt & 38 & 87 & 31.5 & 12 & $\begin{array}{l}\text { Al reconstruction } \\
\text { plate }\end{array}$ & RTEN \\
\hline Bi et al., $2008^{38}$ & China & 201 & 72 & 39.8 & $10.6(4-21)$ & $\begin{array}{l}\text { Retrograde } \\
\text { percutaneous pin }\end{array}$ & Kirshner pin \\
\hline Ferran et al., $2010^{39}$ & United Kingdom & 133 & 84 & 29.2 & 12 & LCDCP & Rockwood pin \\
\hline Jiang et al., $2012^{40} \dagger$ & China & 64 & 63 & 42.5 & 24 & LCP & MIPPO \\
\hline Shen et al., $2008^{41}$ & China & 32 & 56 & 44.2 & 12 & $\begin{array}{l}\text { Superior } \\
\text { reconstruction } \\
\text { plate }\end{array}$ & $\begin{array}{l}\text { 3-dimensional } \\
\text { contoured cortical } \\
\text { plate }\end{array}$ \\
\hline Lubbert et al., $2008^{42}$ & Netherlands & 120 & 84 & NR & 12 & LIPUS & Placebo \\
\hline \multicolumn{8}{|c|}{ 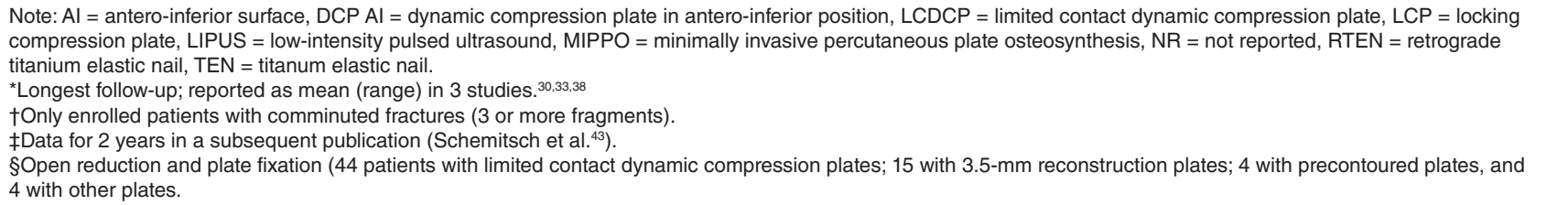 } \\
\hline
\end{tabular}


assessors was described in only 1 study, ${ }^{42}$ it was unclear in $2,{ }^{38,41}$ and it was not done in the remaining 12 studies. ${ }^{5,10,30-37,39,40}$ Eight studies were considered to be at low risk for attrition bias, $, 30,33,35-37,40,426$ were classified as high risk, ${ }^{10,31,32,34,39,41}$ and 1 was judged as unclear. ${ }^{38}$ Reporting bias was deemed high in 7 studies, ${ }^{10,30,34,35,37,38,41}$ while 6 were unclear $^{31-33,39,40,42}$ and 2 were considered as low. ${ }^{5,36}$ Agreement between reviewers in the assessment of methodologic quality was excellent (weighted $\kappa$ value $=0.85$ ). The funnel plot did not suggest publication bias (Figure 3). However, the sample of only 8 studies ${ }^{5,10,30-32,34-36}$ limits interpretability. ${ }^{13}$

\section{Secondary operation}

Nonoperative treatment did not confer a greater risk of secondary operation across 8 trials involving 685 patients (RR 1.16, $95 \%$ CI 0.58 to 2.35 ; $p$ for heterogeneity $=0.08, I^{2}=50 \%$ ) (Figure 4). Subgroup analyses suggested an interaction between the type of operative implants (plate versus intramedullary fixation)

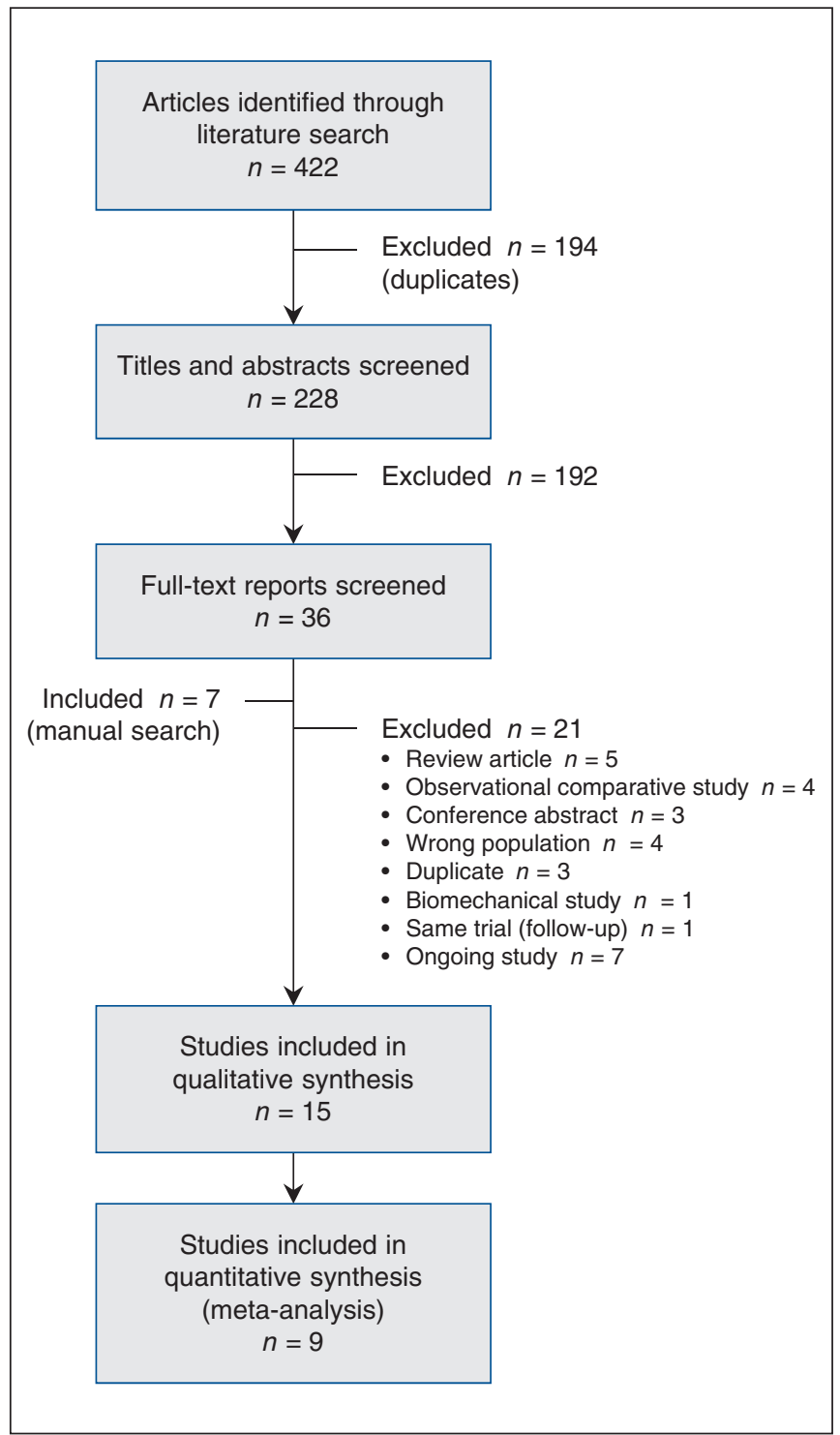

Figure 1: Selection of studies for the meta-analysis. and the need for secondary operation $(p=0.05)$. These findings were robust to sensitivity testing for trials with missing data (complete case analysis: RR 1.07, 95\% CI 0.48 to 2.36; $p$ for heterogeneity $=0.03, I^{2}=60 \%$; arm-level assumption analysis: $\mathrm{RR}$ $1.12,95 \%$ CI 0.52 to 2.41 ; $p$ for heterogeneity $=0.02, I^{2}=62 \%$ ).

Reasons for reoperation in the operative group commonly included hardware irritation $(54.8 \%)$, infection (19\%) and implant failure or refracture (19\%). Common indications for secondary procedures in nonoperatively managed patients were symptomatic nonunion $(57.1 \%)$ and symptomatic malunion $(28.6 \%)$.

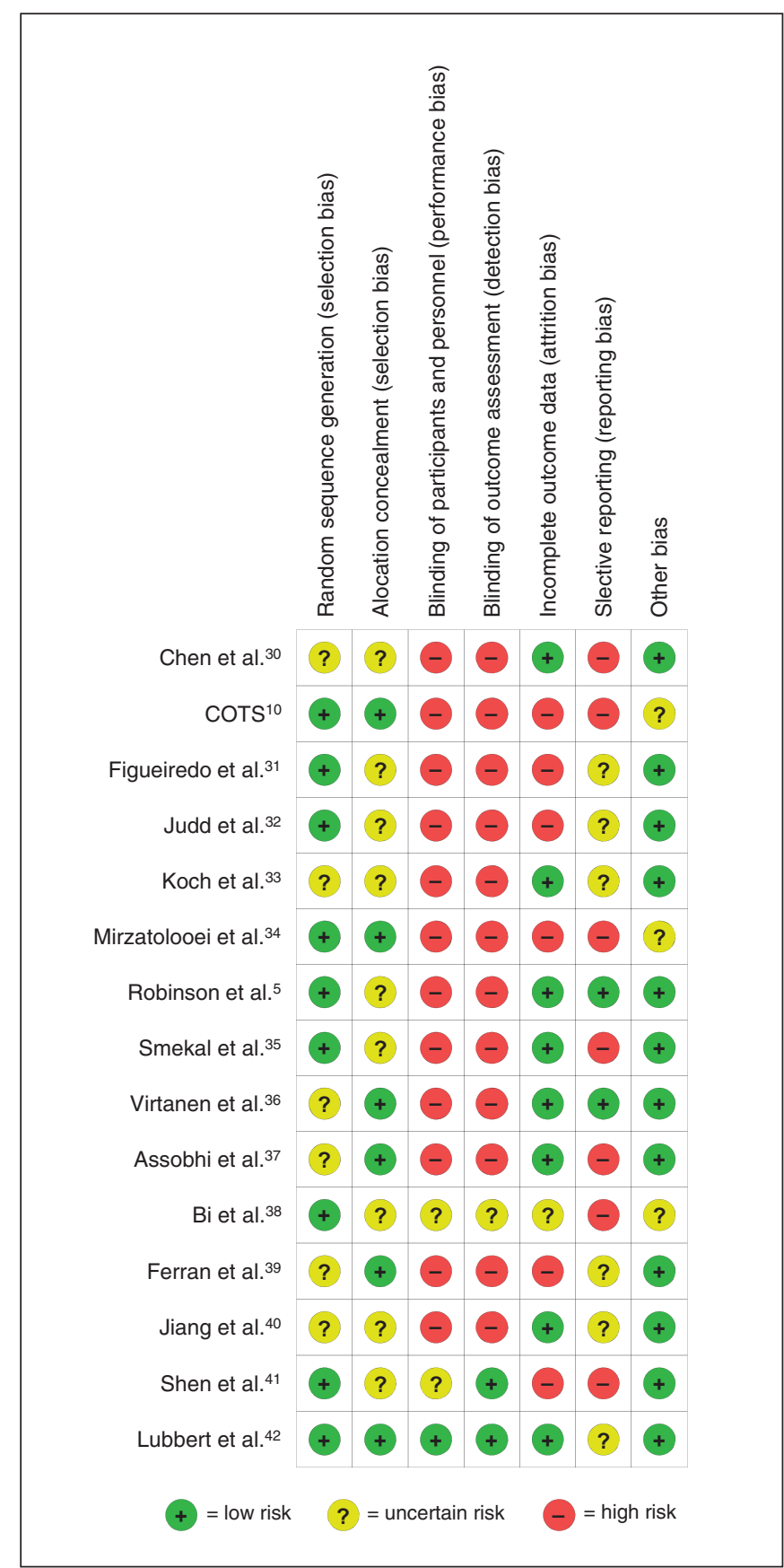

Figure 2: Risk-of-bias assessment of randomized controlled trials included in the meta-analysis. COTS = Canadian Orthopaedic Trauma Society. 


\section{All complications}

Across 8 studies, there were 77 (23\%) complications in 340 patients in the operative group and 88 (26\%) complications in 345 patients managed nonoperatively (Table 2). Operative and nonoperative treatments did not differ in complication risk (RR 0.90, $95 \%$ CI 0.55 to $1.50 ; p$ for heterogeneity $=0.01, I^{2}=63 \%$ ) (Figure 5). Between-trial heterogeneity was not explained by subgroup analysis for type of operative implant $(p=0.2)$. Sensitivity

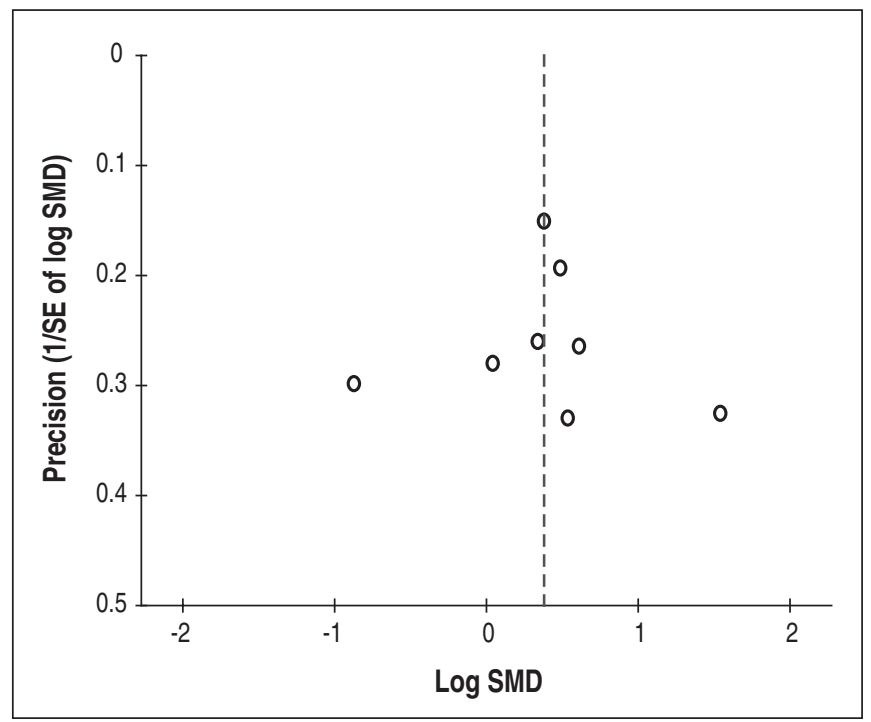

Figure 3: Funnel plot, to assess whether there is evidence of publication bias among trials of operative versus nonoperative treatment of acute displaced midshaft clavicle fractures. The standard normal deviate of the SMD (natural logarithm of the SMD divided by its standard error [SE]) is plotted against the estimate's precision (inverse of the $\mathrm{SE}) . \mathrm{SMD}=$ standardized mean difference. testing for trials with missing data conferred a similar result (complete case analysis: RR $0.81,95 \%$ CI 0.47 to 1.40 ; $p$ for heterogeneity $=0.003, I^{2}=70 \%$; arm-level assumption analysis: RR $0.86,95 \%$ CI 0.47 to 1.56 ; $p$ for heterogeneity $<0.001, I^{2}=78 \%$ ).

\section{Functional scores}

Seven of the 8 studies included in the pooled analysis evaluated shoulder function at 1 year; the other trial ${ }^{35}$ assessed it at 2 years. Long-term function favoured operative treatment (SMD 0.38, 95\% CI 0.00 to 0.75 ; $p$ for heterogeneity $<0.001$, $\left.I^{2}=79 \%\right)$. This is equivalent to an estimated DASH score mean difference of 3.5 (95\% CI 0.00 to 6.85 ). The treatment effect failed to exceed the threshold of patient importance based on the MID (10.2 points) (Figure 6). Subgroup analysis to assess the potential risk of selection bias for overall function at 1 year or longer did not differ appreciably from the primary analysis (low risk: $p=0.06, I^{2}=87 \%$; unclear risk: $p=0.4, I^{2}=73 \%$ ). There was residual heterogeneity when we compared high $(p<$ $\left.0.001, I^{2}=0 \%\right)$ and low $\left(p=0.5, I^{2}=93 \%\right)$ risk of attrition bias.

\section{Comparison of operative interventions}

Comparison of surgical implants with respect to indications for reoperation, all complications and long-term function have been summarized in Table 3 . The functional outcome at 1 year was similar between groups in all trials, showing no significant difference irrespective of the implant used for internal fixation.

\section{Comparison of nonoperative treatments}

The available evidence for conservative treatment of acute displaced midshaft clavicle fractures from a placebo-controlled trial of high methodologic quality found no difference in clinical fracture healing between patients receiving low-intensity

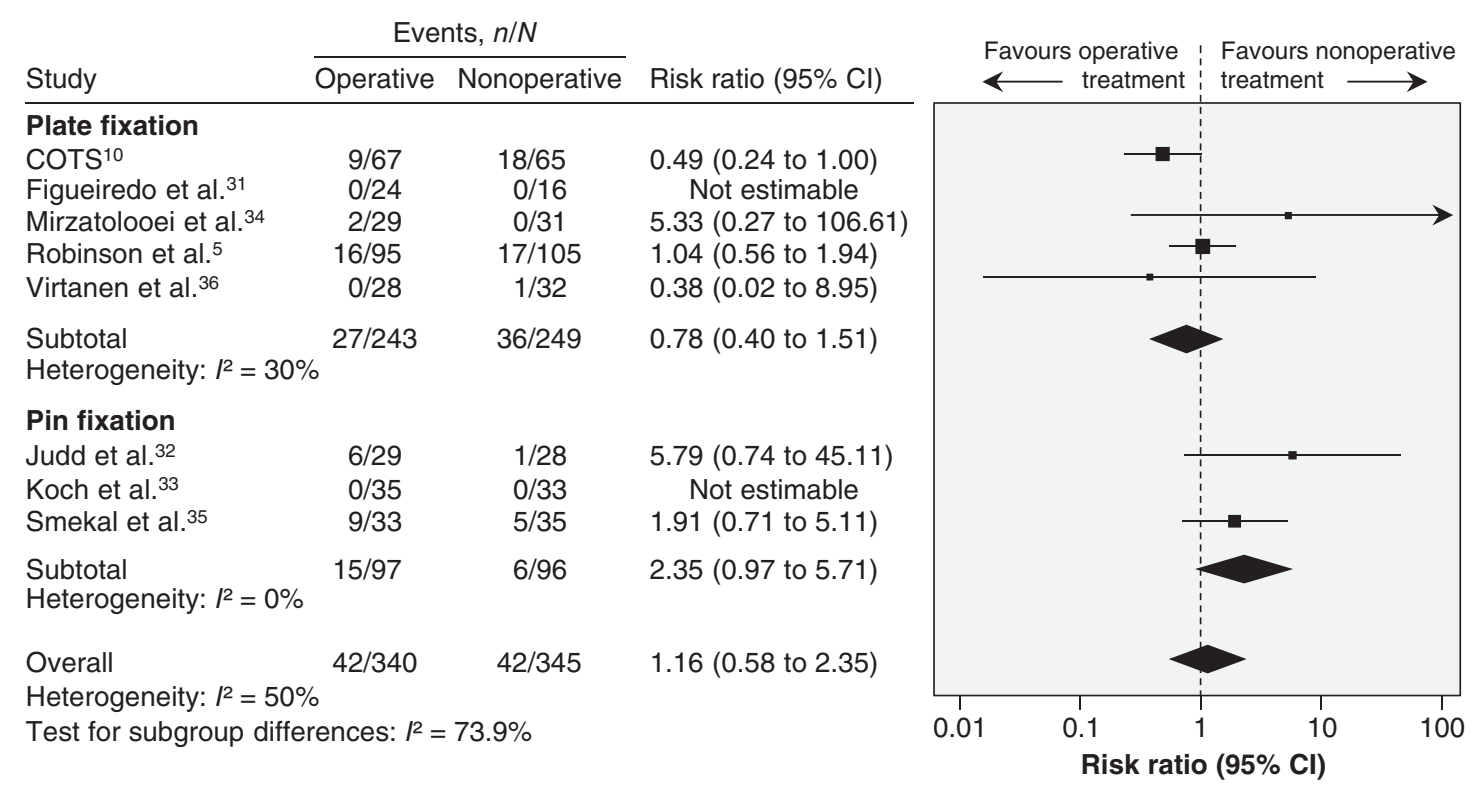

Figure 4: Pooled estimates of secondary operation between operative and nonoperative groups. Values less than 1.0 favour operative treatment. Note: The $N$ values in the study by Figueiredo et al. (24 operative, 16 nonoperative) are the numbers who completed the study and not the numbers initially randomized. $\mathrm{Cl}=$ confidence interval. 
pulsed ultrasound and those given placebo. ${ }^{42}$ Of the 101 patients who completed the trial, 9 (8.9\%; 4 placebo, 5 active) underwent subsequent operative treatment with open reduction and internal fixation for fractures that did not heal according to the patients.

\section{Interpretation}

The results of our meta-analysis of the relative effects of operative versus nonoperative intervention for acute displaced midshaft clavicle fractures suggest that the incidence of secondary operations and all complications did not differ between the operative and nonoperative groups. There was modest functional improvement at 1 year in the operative group; however, this difference was clinically unimportant. Based on the GRADE criteria (Table 4), the systematic review and meta-analysis found a lack of high-quality evidence to inform the management of acute displaced midshaft clavicle fractures.

A previous systematic review ${ }^{1}$ captured secondary procedures and reported a pooled estimate of effect favouring the operative group (RR 0.38 , 95\% CI 0.15 to 0.99 ), a finding that is inconsistent with our review. Our review added a recent RCT and increased the pooled sample size by more than one-third, which likely explains in part the inconsistency. This discrepancy may be further explained by the fact that our review captured hardware irritation and infection as indications for nonroutine secondary procedures, whereas the previous systematic review did not. ${ }^{1}$ Although the risk of a secondary procedure was similar between both treatment groups, the reasons for delayed intervention were quite different. Hardware removal because of hardware irritation was the most

\begin{tabular}{|c|c|c|c|c|}
\hline \multirow[b]{2}{*}{ Study } & \multicolumn{2}{|l|}{$\begin{array}{l}\text { Operative group } \\
\qquad n=340\end{array}$} & \multicolumn{2}{|c|}{$\begin{array}{l}\text { Nonoperative group } \\
\qquad n=345\end{array}$} \\
\hline & Complication* & $\begin{array}{c}\text { No. } \\
\text { of patients }\end{array}$ & Complication* & $\begin{array}{c}\text { No. } \\
\text { of patients }\end{array}$ \\
\hline \multirow[t]{5}{*}{ COTS $^{10}$} & Operative procedure & 9 & Operative procedure & 18 \\
\hline & Symptomatic nonunion & 2 & Neurologic symptoms & 7 \\
\hline & Neurologic symptoms & 8 & Complex regional pain syndrome & 1 \\
\hline & Abnormality of AC or SC joint & 2 & Abnormality of $\mathrm{AC}$ or $\mathrm{SC}$ joint & 3 \\
\hline & Other† & 2 & Other† & 2 \\
\hline \multirow[t]{2}{*}{ Figueiredo et al. ${ }^{31}$} & Symptomatic nonunion & 2 & Symptompatic nonunion & 1 \\
\hline & Implant failure & 1 & Adhesive capsulitis & 2 \\
\hline \multirow[t]{4}{*}{ Judd et al. ${ }^{32}$} & Operative procedure & 6 & Operative procedure & 1 \\
\hline & Refracture & 1 & Refracture & 1 \\
\hline & Wound infection & 3 & & \\
\hline & Neurologic symptoms & 1 & & \\
\hline Koch et al. ${ }^{33}$ & NR & & NR & \\
\hline \multirow[t]{3}{*}{ Mirzatolooei et al. ${ }^{34}$} & Operative procedure & 2 & Symptomatic malunion & 19 \\
\hline & Symptomatic malunion & 4 & Neurologic symptoms & 2 \\
\hline & Early mechanical failure & 1 & & \\
\hline \multirow[t]{4}{*}{ Robinson et al. ${ }^{5}$} & Operative procedure & 16 & Operative procedure & 17 \\
\hline & Wound infection & 2 & Rotator cuff impingement & 1 \\
\hline & Wound dehiscence & 1 & & \\
\hline & Rotator cuff impingement & 2 & & \\
\hline \multirow[t]{2}{*}{ Smekal et al. ${ }^{35}$} & Operative procedure & 9 & Operative procedure & 5 \\
\hline & & & Neurologic symptoms & 3 \\
\hline \multirow[t]{3}{*}{ Virtanen et al. ${ }^{36}$} & Refracture & 1 & Operative procedure & 1 \\
\hline & Early mechanical failure & 1 & Symptomatic malunion & 2 \\
\hline & Hardware irritation & 1 & Refracture & 2 \\
\hline Total & & 77 & & 88 \\
\hline $\begin{array}{l}\text { Note: } A C=\text { acromioclavic } \\
{ }^{*} \text { Operative procedure }=0 \\
\dagger \text { Not described. }\end{array}$ & $\begin{array}{l}\mathrm{VR}=\text { not reported, } \mathrm{SC}=\text { sternocla } \\
\text { cation that was severe and consec }\end{array}$ & required se & y operation. & \\
\hline
\end{tabular}


common indication for a secondary procedure in the operative group, as compared with symptomatic nonunion in the nonoperative group. The latter indication would typically require open reduction and internal fixation with or without bone graft, which may be associated with a higher risk of complications and a longer rehabilitation period than hardware removal because of hardware irritation.

\section{Limitations}

Although our population was homogenous in terms of major demographic characteristics, heterogeneity was identified across our key outcomes $\left(I^{2}=50 \%-79 \%\right)$. There was substantial heterogeneity in terms of all complications and longterm function, which could be attributed in part to the inclusion of 2 studies ${ }^{32,34}$ in our pooled analysis. Judd and

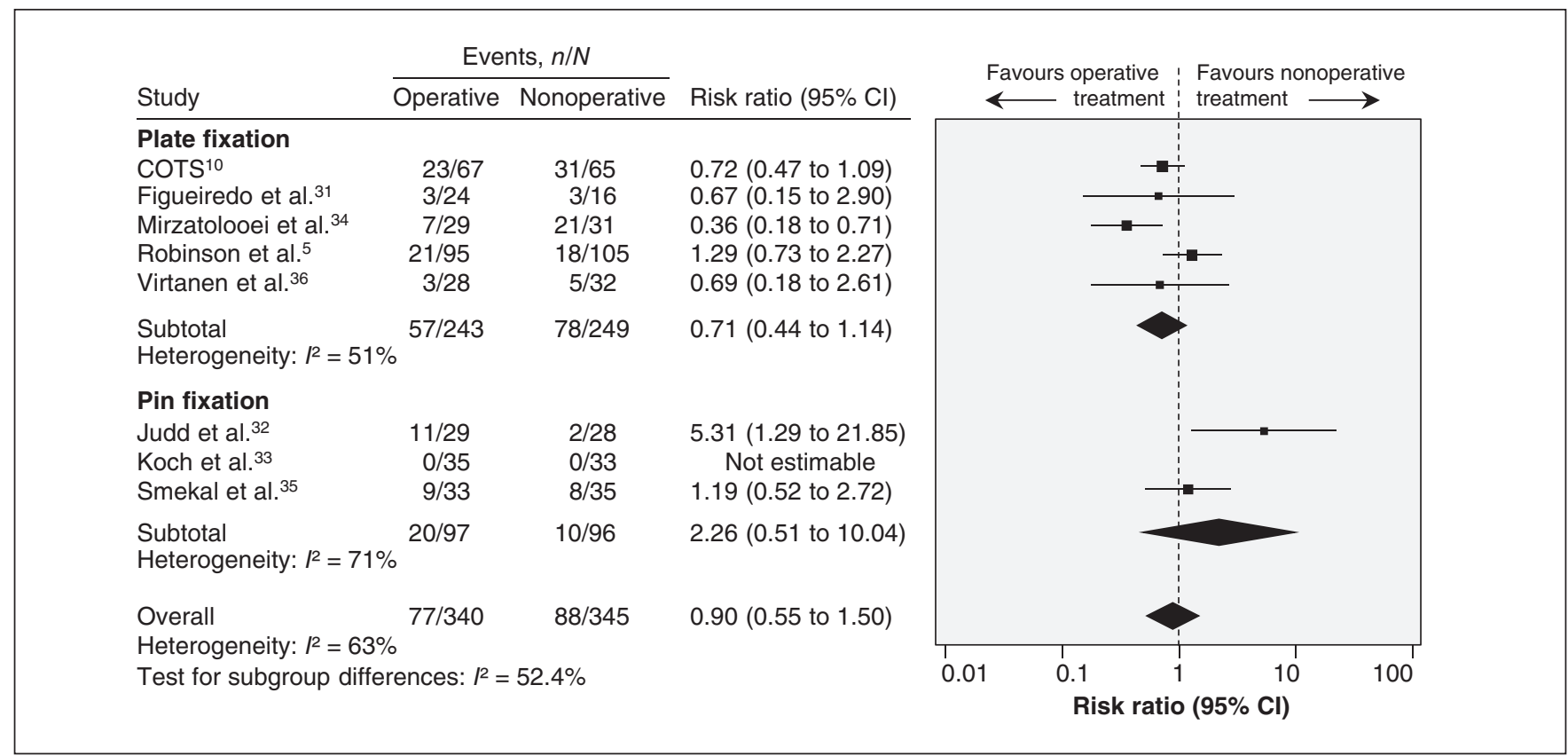

Figure 5: Pooled estimates of all complications between operative and nonoperative groups. Values less than 1.0 favour operative treatment. Note: The $N$ values in the study by Figueiredo et al. (24 operative, 16 nonoperative) are the numbers who completed the study and not the numbers initially randomized. $\mathrm{Cl}=$ confidence interval.

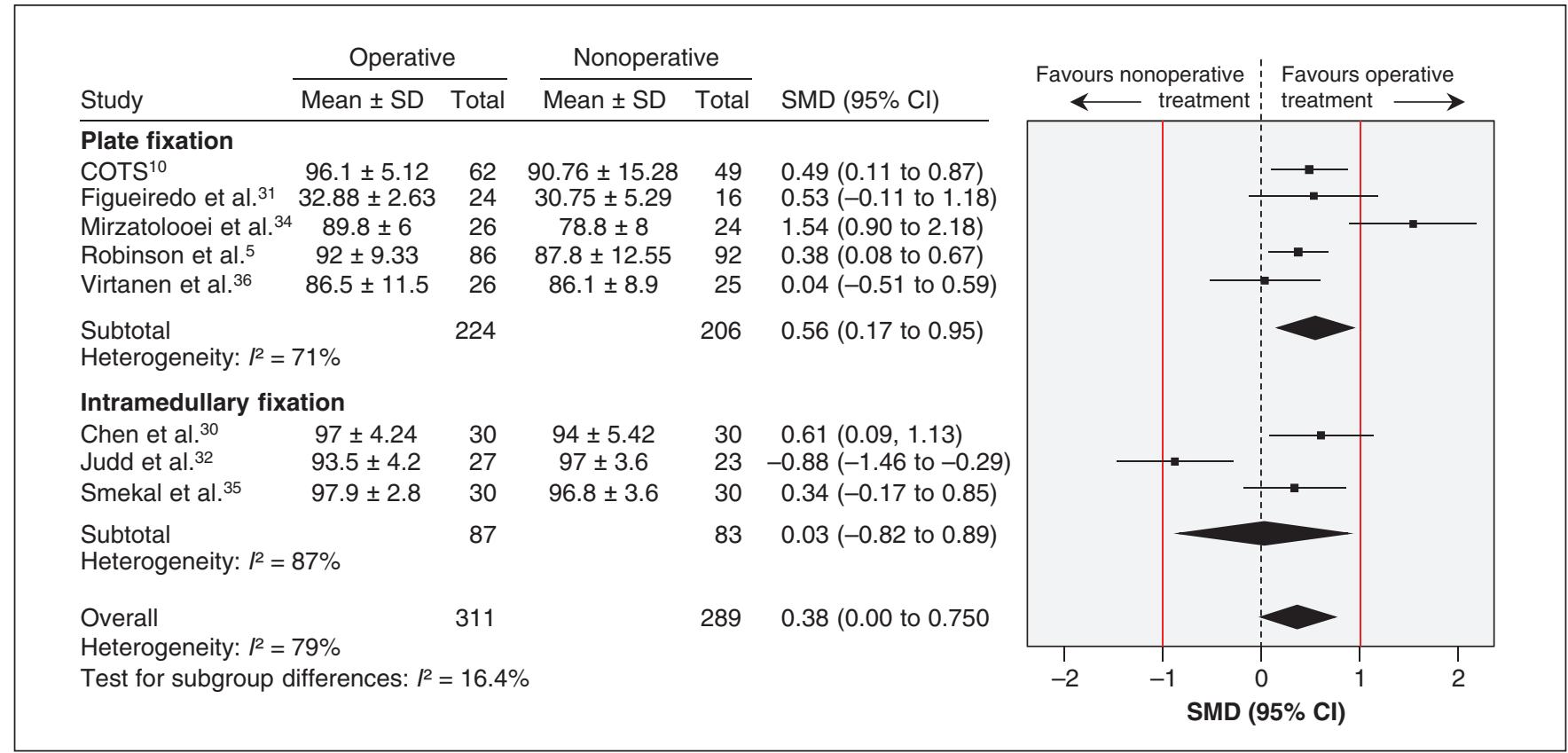

Figure 6: Pooled long-term function ( $\geq 1 \mathrm{yr}$ ) following operative and nonoperative treatment. Standardized mean differences (SMDs) greater than zero favour operative treatment. Red lines show a zone of clinical equivalence based on a minimal important difference of 10.2 points on the Disabilities of the Arm, Shoulder and Hand (DASH) questionnaire. $\mathrm{Cl}=$ confidence interval, SD = standard deviation. 
colleagues $^{32}$ reported a relatively high complication rate (41\%) compared with the other included studies, a difference likely due to the choice of implant. Mirzatolooei and colleagues $^{34}$ included comminution (defined as more than 2 fragments in the fracture site) as an inclusion criterion when assessing patients for eligibility; $33 \%$ of the participants in their trial had a fracture with more than 3 fragments. Furthermore, all of the pooled studies excluded open fractures except for this same study, in which $20 \%$ of patients had an open clavicle fracture. ${ }^{34}$ The SMD can be vulnerable to widely varying $\mathrm{SDs},{ }^{13}$ which also may have contributed to the substantial between-study heterogeneity in the pooled analysis for long-term function.

Operative procedures using plates and screws are technically distinct from those using intramedullary devices; however, pooling studies of these techniques separately did not explain the high heterogeneity seen in the primary analyses. Pooling trials at high or unclear risk of selection or detection bias independently from those at low risk did not lower the heterogeneity present in the primary analysis for long-term function. We were unable to perform additional a priori sub- group analyses, because included studies did not provide sufficient information to explore the effects of time to intervention or comminuted fractures on relevant outcomes.

Seven of the 15 trials included in our review inadequately addressed patients lost to follow-up. Markedly, among the trials comparing operative with nonoperative treatments, a greater number of patients lost to follow-up were in the nonoperative group, which may limit the precision of our estimates of treatment effects and thus overall generalizability.

\section{Implications for practice}

Adopting a policy of routine internal fixation for acute displaced midshaft clavicle fractures is contentious, because surgery carries the burden of increased hospital expenditures and inherent surgical complications, including deep or superficial wound infection, hardware irritation, hardware failure or migration, and poor cosmesis of a surgical scar., In a recent retrospective population-based study in Ontario involving 1350 patients who underwent open reduction and internal fixation for a closed isolated midshaft clavicle frac-

\begin{tabular}{|c|c|c|c|c|c|c|}
\hline Study & $\begin{array}{l}\text { Secondary } \\
\text { operations }\end{array}$ & $\begin{array}{l}\text { Risk ratio } \\
(95 \% \mathrm{Cl})\end{array}$ & $\begin{array}{l}\text { Complications not } \\
\text { requiring surgical } \\
\text { intervention }\end{array}$ & $\begin{array}{l}\text { Risk ratio } \\
(95 \% \mathrm{Cl})\end{array}$ & $\begin{array}{l}\text { Functional } \\
\text { outcome: constant } \\
\text { score (1 yr) }\end{array}$ & $\begin{array}{c}\text { Mean } \\
\text { difference } \\
(95 \% \mathrm{Cl})\end{array}$ \\
\hline \multicolumn{7}{|l|}{ Assobhi et al. ${ }^{37}$} \\
\hline $\begin{array}{l}\text { Al reconstruction } \\
\text { plate }(n=19)\end{array}$ & $\begin{array}{l}1 \text { nonunion } \\
1 \text { wound infection and } \\
\text { implant loosening }\end{array}$ & $\begin{array}{c}0.67 \\
(0.13 \text { to } 3.55)\end{array}$ & 1 nonunion & $\begin{array}{c}1.00 \\
(0.23 \text { to } 4.34)\end{array}$ & 89.8 (11.3) & $\begin{array}{c}-5.60 \\
(-11.21 \text { to } 0.01)\end{array}$ \\
\hline RTEN $(n=19)$ & 3 prominent nails & & NR & & $95.5(5.3)$ & \\
\hline \multicolumn{7}{|l|}{ Bi et al. ${ }^{38}$} \\
\hline $\begin{array}{l}\text { Retrograde } \\
\text { percutaneous pin } \\
(n=101)\end{array}$ & NR & NA & NR & $\begin{array}{c}0.11 \\
(0.01 \text { to } 2.02)\end{array}$ & NR & NA \\
\hline Kirshner pin $(n=100)$ & NR & & 4 nonunions & & NR & \\
\hline \multicolumn{7}{|l|}{ Ferran et al. ${ }^{39}$} \\
\hline Rockwood pin $(n=17)$ & 1 implant loosening & $\begin{array}{c}0.22 \\
(0.06 \text { to } 0.88)\end{array}$ & NR & $\begin{array}{c}0.22 \\
(0.06 \text { to } 0.88)\end{array}$ & $92.1(6)^{*}$ & $\begin{array}{c}3.4 \\
(-2.02 \text { to } 8.82)\end{array}$ \\
\hline $\operatorname{LCDCP}(n=15)$ & $\begin{array}{l}3 \text { superficial infections } \\
1 \text { persistent pain } \\
4 \text { hardware irritation }\end{array}$ & & NR & & $88.7(9.1)^{\star}$ & \\
\hline \multicolumn{7}{|l|}{ Jiang et al. ${ }^{40}$} \\
\hline $\begin{array}{l}\text { MIPPO }(n=32) \\
\operatorname{LCP}(n=32)\end{array}$ & $\begin{array}{l}\text { NR } \\
\text { NR }\end{array}$ & NA & $\begin{array}{l}\text { NR } \\
\text { NR }\end{array}$ & NA & $\begin{array}{l}96 \dagger \\
95.7 \dagger\end{array}$ & $\begin{array}{c}0.30 \\
(-4.70 \text { to } 5.30)\end{array}$ \\
\hline \multicolumn{7}{|l|}{ Shen et al. ${ }^{41}$} \\
\hline $\begin{array}{l}\text { 3D contoured cortical } \\
\text { plate }(n=67)\end{array}$ & 1 delayed union & $\begin{array}{c}0.12 \\
(0.02 \text { to } 0.96)\end{array}$ & $\begin{array}{l}3 \text { "symptomatic } \\
\text { patients" }\end{array}$ & $\begin{array}{c}0.20 \\
(0.06 \text { to } 0.65)\end{array}$ & NR & NA \\
\hline $\begin{array}{l}\text { Superior reconstruction } \\
\text { plate }(n=66)\end{array}$ & 8 delayed unions & & $\begin{array}{l}15 \text { "symptomatic } \\
\text { patients" }\end{array}$ & & & \\
\hline
\end{tabular}


ture, ${ }^{44}$ the reoperation rate was $24.6 \%$, which is about twice as high as our finding. Fifty percent of the patients had their hardware removed after 12 months (median 12 mo, interquartile range 5.8 to $16.1 \mathrm{mo}$ ), whereas more than half of the trials included in our meta-analysis had a follow-up period of only 12 months.

There are important differences in design characteristics between observational studies and randomized trials that may be responsible for contradictory estimates of treatment effects. First, infrequent events and long-term clinical outcomes are often difficult to study in randomized trials and may be more suitably investigated in large observational studies. ${ }^{45}$ Second, it is plausible that surgeons involved in most trials may have substantial generic surgical expertise and expertise with the intervention under study, which may not represent the skill level of the surgical community in which the intervention will be implemented. ${ }^{46}$ Despite the obvious discrepancy between the observational studies and RCTs in terms of reoperation, it is incumbent upon us to recognize the complementary roles of both sources of information and understand that the complete body of evidence could have profound clinical implications.

\section{Implications for research}

Recurrent study design limitations, including small samples, lack of blinding and loss to follow-up, must be overcome to improve the quality of evidence from future RCTs. Unified evaluation criteria for outcomes such as nonunion and malunion should be applied to all trials evaluating interventions to treat these fractures. The most recent RCT included in our review evaluated absence from work and found that, although the timing of return to work was dependent on the nature of the patient's work, no significant differences were found between the study groups in terms of total time off work following injury $(p=0.7) .^{5}$ Therefore, if long-term function is seemingly similar between treatment groups, further investigation should aim to determine whether early functional improvements ( $<6 \mathrm{mo})$ differ significantly between operative and nonoperative groups.

The trials included in our review did not provide sufficient evidence to suggest which patients might benefit the most from surgical treatment. It remains unclear whether certain fracture characteristics such as shortening, displacement or comminution can reliably predict patient-focused functional outcomes. ${ }^{47}$ A study assessing the reliability of fellowshiptrained shoulder and sports medicine orthopedic surgeons in classifying midshaft clavicle fractures via standard plain radiographs and the agreement in treating the fractures showed moderate to strong agreement for degree of displacement and for comminution; however, the standard plain radiographs were insufficient to reliably determine the degree of shortening of clavicle fractures and the need for surgery among the surgeons. ${ }^{48}$ Further investigations are required to develop better criteria to avoid under- or overestimating fracture severity. Future trials should aim to better identify the subgroup of patients who might benefit from primary surgical intervention and to establish optimal surgical indications. Their findings would help focus the use of surgical resources on appropriate candidates and prevent undertreatment of the injury nonoperatively.

Table 4: GRADE summary of findings for operative compared with nonoperative treatment for acute displaced midshaft clavicle fractures

Patient or population: Patients with an acute displaced midshaft clavicle fracture

Intervention: Operative treatment (plate or intramedullary device)

Comparison: Nonoperative treatment (standard sling, figure of 8 dressing, or a collar and cuff)

Outcomes: Secondary operations, all other complications, long-term function

\begin{tabular}{|c|c|c|c|}
\hline Outcome & $\begin{array}{l}\text { No. of participants } \\
\text { (studies) }\end{array}$ & $\begin{array}{l}\text { Anticipated effects, } \\
\text { risk with operative treatment }(95 \% \mathrm{Cl})\end{array}$ & $\begin{array}{l}\text { GRADE quality } \\
\text { of evidence }\end{array}$ \\
\hline $\begin{array}{l}\text { Secondary operation } \\
\text { Follow-up: } 12 \text { mo }\end{array}$ & $685(8)$ & $\begin{array}{l}\text { Evidence suggested higher incidence of secondary } \\
\text { operation in operative group (RR } 1.16,95 \% \mathrm{Cl} 0.58 \text { to } 2.35 \text { ), } \\
\text { but difference was not statistically significant }\end{array}$ & Low* $\ddagger$ \\
\hline $\begin{array}{l}\text { All other complications } \\
\text { Follow-up: } 12 \text { mo }\end{array}$ & $685(8)$ & $\begin{array}{l}\text { Evidence suggested slightly lower number of complications } \\
\text { in the operative group (RR } 0.9,95 \% \mathrm{Cl} 0.55 \text { to } 1.5 \text { ), but } \\
\text { difference was not statistically significant }\end{array}$ & Low* $\ddagger$ \\
\hline $\begin{array}{l}\text { Long-term function } \\
\text { Follow-up: ( } \geq 1 \mathrm{yr})\end{array}$ & $611(8)$ & $\begin{array}{l}\text { Mean long-term shoulder function was } 0.38 \text { SDs higher in } \\
\text { operative group ( } 0.22 \text { lower to } 0.54 \text { higher }) \dagger\end{array}$ & Very low*§ \\
\hline
\end{tabular}

Note: $\mathrm{Cl}=$ confidence interval, GRADE = Grading of Recommendations Assessment, Development, and Evaluation, MID = minimal important difference, RR = risk ratio, SD = standard deviation.

*Downgraded because of risk of bias (lack of blinding study personnel, unclear reporting of allocation concealment and sequence generation).

†Effect failed to exceed MID (smallest effect that an informed patient would perceive as beneficial enough to justify a change in management).

‡Downgraded because of fragility of few events.

§Downgraded for imprecision and inconsistency.

GRADE Working Group grades of evidence:

High quality: Further research is very unlikely to change our confidence in the estimate of effect.

Moderate quality: Further research is likely to have an important impact on our confidence in the estimate of effect and may change the estimate.

Low quality: Further research is very likely to have an important impact on our confidence in the estimate of effect and is likely to change the estimate.

Very low quality: We are very uncertain about the estimate. 


\section{Conclusion}

Current evidence does not support the routine use of internal fixation for the treatment of displaced midshaft clavicle fractures. Evidence for the type of implant or approach to nonoperative treatment was inconclusive, and complication rates were high regardless of the management approach.

\section{References}

1. Lenza M, Johnston RV, Belloti JC, et al. Surgical versus conservative interventions for treating fractures of the middle third of the clavicle. Cochrane Database Syst Rev 2013;(6):CD009363.

2. McKee MD. Clavicle fractures in 2010: Sling/swathe or open reduction and internal fixation? Orthop Clin North Am 2010;41:225-31.

3. Nordqvist A, Petersson C. The incidence of fractures of the clavicle. Clin Orthop Relat Res 1994; (300):127-32.

4. Nowak J, Mallmin H, Larsson S. The aetiology and epidemiology of clavicular fractures. A prospective study during a two-year period in Uppsala, Sweden. Injury 2000;31:353-8.

5. Robinson CM, Goudie EB, Murray IR, et al. Open reduction and plate fixation versus nonoperative treatment for displaced midshaft clavicular fractures: a multicenter, randomized, controlled trial. 7 Bone foint Surg Am 2013;95:1576-84.

6. Van Tassel D, Owens BD, Pointer L, et al. Incidence of clavicle fractures in sports: analysis of the NEISS Database. Int 7 Sports Med 2014;35:83-6.

7. Neer CS II. Nonunion of the clavicle. 7 Am Med Assoc 1960;172:1006-11.

8. Rowe CR. An atlas of anatomy and treatment of midclavicular fractures. Clin Orthop Relat Res 1968; (58):29-42.

9. McKee RC, Whelan DB, Schemitsch EH, et al. Operative versus nonoperative care of displaced midshaft clavicular fractures: a meta-analysis of randomized clinical trials. 7 Bone foint Surg Am 2012;94:675-84.

10. Canadian Orthopaedic Trauma Society. Nonoperative treatment compared with plate fixation of displaced midshaft clavicular fractures. A multicenter, randomized clinical trial. $\mathcal{F}$ Bone foint Surg Am 2007;89:1-10.

11. $\mathrm{Xu} \mathrm{J}, \mathrm{Xu} \mathrm{L}, \mathrm{Xu} \mathrm{W}$, et al. Operative versus nonoperative treatment in the management of midshaft clavicular fractures: a meta-analysis of randomized controlled trials. 7 Shoulder Elbow Surg 2014;23:173-81.

12. Liu GD, Tong SL, Ou S, et al. Operative versus non-operative treatment for clavicle fracture: a meta-analysis. Int Orthop 2013;37:1495-500.

13. Higgins JPT, Green S, editors. Cochrane handbook for systematic reviews of interventions. Version 5.1.0 [updated March 2011]. The Cochrane Collaboration; 2011.

14. Moher D, Liberati A, Tetzlaff J, et al. Preferred reporting items for systematic reviews and meta-analyses: the PRISMA statement. Ann Intern Med 2009; 151:264-9.

15. Wilczynski NL, McKibbon KA, Haynes RB. Enhancing retrieval of best evidence for health care from bibliographic databases: calibration of the hand search of the literature. Stud Health Technol Inform 2001;84:390-3.

16. Guyatt GH, Oxman AD, Kunz R, et al. What is "quality of evidence" and why is it important to clinicians? BM7 2008;336:995-8.

17. Akl EA, Johnston BC, Alonso-Coello P, et al. Addressing dichotomous data for participants excluded from trial analysis: a guide for systematic reviewers. PLoS ONE 2013;8:e57132.

18. DerSimonian R, Laird N. Meta-analysis in clinical trials. Control Clin Trials 1986;7:177-88.

19. Puhan MA, Soesilo I, Guyatt GH, et al. Combining scores from different patient reported outcome measures in meta-analyses: When is it justified? Health Qual Life Outcomes 2006;4:94.

20. Bannuru RR, Vaysbrot EE, McIntyre LF. Did the American Academy of Orthopaedic Surgeons osteoarthritis guidelines miss the mark? Arthroscopy 2014;30:86-9.

21. Carragee EJ. The rise and fall of the "minimum clinically important difference." Spine $\mathcal{7}$ 2010;10:283-4.

22. Copay AG, Subach BR, Glassman SD, et al. Understanding the minimum clinically important difference: a review of concepts and methods. Spine 7 2007;7:541-6.

23. Gatchel RJ, Mayer TG. Testing minimal clinically important difference: Consensus or conundrum? Spine 72010;10:321-7.

24. Jaeschke R, Singer J, Guyatt GH. Measurement of health status. Ascertaining the minimal clinically important difference. Control Clin Trials 1989;10:407-15.

25. Angst F, Schwyzer HK, Aeschlimann A, et al. Measures of adult shoulder function: Disabilities of the Arm, Shoulder, and Hand Questionnaire (DASH) and its short version (QuickDASH), Shoulder Pain and Disability Index (SPADI), American Shoulder and Elbow Surgeons (ASES) Society Standardized Shoulder Assessment Form, Constant (Murley) Score (CS), Simple Shoulder Test (SST), Oxford Shoulder Score (OSS), Shoulder Disability Questionnaire (SDQ), and Western Ontario Shoulder Instability Index (WOSI). Arthritis Care Res (Hoboken) 2011;63:S174-88.

26. Schmitt JS, Di Fabio RP. Reliable change and minimum important difference (MID) proportions facilitated group responsiveness comparisons using individual threshold criteria. 7 Clin Epidemiol 2004;57:1008-18.

27. Thorlund K, Walter SD, Johnston BC, et al. Pooling health-related quality of life outcomes in meta-analysis - a tutorial and review of methods for enhancing interpretability. Res Synth Methods 2011;2:188-203.
28. Landis JR, Koch GG. The measurement of observer agreement for categorical data. Biometrics 1977;33:159-74.

29. Orwin RG. Evaluating coding decisions. In: Cooper H, Hedges LV, editors. The handbook of research synthesis. New York: Russell Sage Foundation; 1994:139-62.

30. Chen QY, Kou DQ, Cheng XJ, et al. Intramedullary nailing of clavicular midshaft fractures in adults using titanium elastic nail. Chin 7 Traumatol 2011; 14:269-76.

31. Figueiredo E, Neves E, Yoshizawa H Jr, et al. Prospective randomized study comparing surgical treatments using anterior plate and non-surgical management of fractures of the middle third of the clavicle. Rev Bras Ortop 2008;43:419-25.

32. Judd DB, Pallis MP, Smith E, et al. Acute operative stabilization versus nonoperative management of clavicle fractures. Am 7 Orthop 2009;38:341-5.

33. Koch HJ, Raschka C, Tonus C, et al. The intramedullary osteosynthesis of the diaphyseal fracture of the clavicle compared to conservative treatment. Dtsch $Z$ Sportmed 2008;59:91-4.

34. Mirzatolooei F. Comparison between operative and nonoperative treatment methods in the management of comminuted fractures of the clavicle. Acta Orthop Traumatol Turc 2011;45:34-40.

35. Smekal V, Struve P, Wambacher M, et al. Elastic stable intramedullary nailing versus nonoperative treatment of displaced midshaft clavicular fractures: a randomized, controlled, clinical trial. 7 Orthop Trauma 2009;23:106-12.

36. Virtanen KJ, Remes V, Pajarinen J, et al. Sling compared with plate osteosynthesis for treatment of displaced midshaft clavicular fractures: a randomized clinical trial. 7 Bone foint Surg Am 2012;94:1546-53.

37. Assobhi JE. Reconstruction plate versus minimal invasive retrograde titanium elastic nail fixation for displaced midclavicular fractures. 7 Orthop Traumatol 2011;12:185-92.

38. Bi HZ, Yang MQ, Tan YC, et al. The randomized controlled trial of the treatment for clavicular fracture by rotatory manual reduction with forceps holder and retrograde percutaneous pinning transfixation [article in Chinese]. Zhongguo Gu Shang 2008;21:490-3.

39. Ferran NA, Hodgson P, Vannet N, et al. Locked intramedullary fixation vs plating for displaced and shortened mid-shaft clavicle fractures: a randomized clinical trial. 7 Shoulder Elbow Surg 2010;19:783-9.

40. Jiang H. Operative treatment of clavicle midshaft fractures using a locking compression plate: comparison between mini-invasive plate osteosynthesis (MIPPO) technique and conventional open reduction. Orthop Traumatol Surg Res 2012;98:666-71.

41. Shen JW, Tong PJ, Qu HB. A three-dimensional reconstruction plate for displaced midshaft fractures of the clavicle. F Bone foint Surg Br 2008;90:1495-8.

42. Lubbert PH, van der Rijt RH, Hoorntje LE, et al. Low-intensity pulsed ultrasound (LIPUS) in fresh clavicle fractures: a multi-centre double blind randomised controlled trial. Injury 2008;39:1444-52.

43. Schemitsch LA, Schemitsch EH, Veillette C, et al. Function plateaus by one year in patients with surgically treated displaced midshaft clavicle fractures. Clin Orthop Relat Res 2011;469:3351-5.

44. Leroux T, Wasserstein D, Henry P, et al. Rate of and risk factors for reoperations after open reduction and internal fixation of midshaft clavicle fractures. 7 Bone foint Surg Am 2014;96:1119-25.

45. Hoppe DJ, Schemitsch EH, Morshed S, et al. Hierarchy of evidence: where observational studies fit in and why we need them. 7 Bone foint Surg Am 2009;91(Suppl 3):2-9.

46. Cook JA. The challenges faced in the design, conduct and analysis of surgical randomised controlled trials. Trials 2009;10:9.

47. Evaniew N, Simunovic N, McKee MD, et al. Cochrane in CORR: surgical versus conservative interventions for treating fractures of the middle third of the clavicle. Clin Orthop Relat Res 2014;472:2579-85.

48. Jones GL, Bishop JY, Lewis B, et al. Intraobserver and interobserver agreement in the classification and treatment of midshaft clavicle fractures. Am 7 Sports Med 2014;42:1176-81.

Affiliations: Department of Clinical Epidemiology and Biostatistics (Devji, Evaniew, Khoudigian, Bhandari) and Division of Orthopaedic Surgery (Kleinlugtenbelt, Evaniew, Riskevski, Bhandari), McMaster University, Hamilton, Ont.

Contributors: Tahira Devji, Nathan Evaniew, Bill Ristevski and Mohit Bhandari developed the study protocol. Tahira Devji and Ydo Kleinlugtenbelt were responsible for the screening of reports identified through the literature search and for the data abstraction. Tahira Devji, Ydo Kleinlugtenbelt and Shoghag Khoudigian conducted the risk-of-bias and methodologic assessments. Tahira Devji and Shoghag Khoudigian conducted the statistical analyses. Tahira Devji drafted the manuscript. All of the authors revised the manuscript critically for important intellectual content, approved the final version to be published and agreed to act as guarantors of the work.

Supplemental information: For reviewer comments and the original submission of this manuscript, please see www.cmajopen.ca/content/3/4/ E396/suppl/DC1 